\title{
Regressive spondylometaphyseal dysplasia
}

INSERM

\section{Source}

INSERM. (1999). Orphanet: an online rare disease and orphan drug data base. Regressive spondylometaphyseal dysplasia. ORPHA:448267

Regressive spondylometaphyseal dysplasia is a rare, primary bone dysplasia

characterized by mild short stature, rhizomelic shortening of the arms and legs, bowing

of long bones with widened and irregular metaphyses, thoracolumbar kyphosis, and metacarpal shortening. A marked improvement of the radiologic skeletal features is typical. Pelger-Huet anomaly (i.e. dumbbell shape bilobed nuclei of neutrophils) is a characteristic hematological feature of this disease. 